\title{
Una forma de habitar en clave modernizadora. El barrio Arica de Valdivia, 1948- 1960
}

\author{
A way to live in modernizing code. \\ The Arica neighborhood of Valdivia, 1948-1960 \\ Robinson SiLva Hidalgo* \\ aUniversidad Austral de Chile, Chile. $\triangle$ robinson.silva@uach.cl \\ [orcid.org/0000-0003-0175-2194]
}

\section{RESUMEN}

El presente texto busca conocer una forma de habitar colectivamente el territorio valdiviano. En pleno proceso de modernizaciones empujadas por el Estado de compromiso a mediados del siglo XX, los nuevos habitantes de la ciudad, trabajadores de industrias y talleres se apropiaron de territorios periféricos para dotarse de un habitar en consonancia con su nuevo rol en la sociedad, para ello echaron mano a sus saberes y a los elementos sociales, económicos y políticos disponibles. Desde los testimonios de pobladores y los registros documentales del barrio Arica de Valdivia, reconstruimos la historia de los nuevos habitantes y, como resultado, la aparición de una ciudad moderna.

PALABRAS CLAVE: historia social, Chile, Valdivia, habitar, modernización, territorio.

\section{ABSTRACT}

The present text seeks to know a way of collectively inhabiting the Valdivian territory. In the midst of the process of modernizations pushed by the State of compromise in the middle of the twentieth century, the new inhabitants of the city, industrial workers and workshops appropriated peripheral territories to equip themselves to live in harmony with their new role in society, they used their knowledge and the available social, economic and

1 Este trabajo se inserta en el proyecto Anillos: "Patrimonio Industrial: Formas de habitar colectivo en el sur de Chile. Aportes para su puesta en valor y recuperación integrada” financiado por el Programa de Investigación Asociativa PIA-Conicyt SOC1403. Agradecimientos a los ayudantes Mariana Hernández, Matías Jiménez, Nicolás Toledo y Oscar Martel. 
political elements. From the testimonies of settlers and the documentary records of the Arica neighborhood of Valdivia, we reconstruct the history of the new inhabitants and, as a result, the appearance of a modern city.

KEY WORDS: Social History, Chile, Valdivia, Inhabit, Modernization, Territory.

\section{INTRODUCCIÓN}

La aparición de las formas modernas de ciudad en Chile tiene múltiples formas de abordaje, desde un enfoque de historia social, que pone al sujeto en el espacio como elemento central en el análisis, es de suyo importante instalar en el debate historiográfico nuevas formas de comprender la constitución de nuevas formas de habitar ligadas a las comunidades de trabajadores y trabajadoras que aparecen en el escenario de la sociedad y la política del siglo pasado.

Hacia mediados del siglo XX la ciudad de Valdivia se constituía como un polo industrial y eso implicó una importante población obrera, modernizando crecientemente las relaciones sociales de producción. Ese proceso incluyó la denostación de los campesinos precedentes al paisaje industrial, tal como se señala para el casi inglés: “... la Revolución industrial, que vació las zonas rurales de algunas de sus industrias y destruyó el equilibrio entre la vida rural y la urbana, también creó en nuestras mentes una imagen de aislamiento rural..." (Thompson, 2012, p. 445), esa disociación se expresa -a nuestro juicio- en la identificación de lo moderno con lo urbano y lo atrasado con lo rural; desde este punto de vista nos haremos cargo de uno de los conflictos de mayor debate en el período: el acceso a la vivienda para los trabajadores, que nos ayudará a entender de manera patente este proceso modernizador y sus claroscuros, dado la diversidad de formas en la construcción de los barrios para obreros, con multiplicidad de actores en su gestión y por el devenir que tienen sus habitantes a mediados del siglo XX.

Con todo, las ideas y las imágenes del campo y la ciudad conservan la gran fuerza de cada uno de ellos. Esta persistencia tiene una significación comparable solo con el hecho de la gran variación real, social e histórica de las ideas mismas. Claramente, el contraste del campo con la ciudad es una de las principales formas en las cuales nos tornamos conscientes de una parte central de nuestra experiencia de la crisis de nuestra sociedad (Williams, 2017, p. 379).

En el pensamiento de Williams se identifica el proceso de conflicto que los sujetos históricos viven en su tránsito de la vida rural a la urbana y moderna, esa experiencia de la crisis de la que nos habla es la que se trasunta en la instalación de un nuevo habitar, el barrio, el conjunto de viviendas que emerge como nuevo paisaje. 
Hablamos de un nuevo habitar entonces, se une el habitante venido del campo con el que ya tiene un recorrido como obrero en la ciudad, que conoce conventillos y hacinamientos y que se visibiliza como cuerpo necesitado en el cambio de siglo y en adelante (Illanes, 2006, pp. 41-109). Ese sujeto es quien define una nueva forma de estar en el territorio, mediada por la industria y su modernidad implícita es una manera de afrontar nuevas relaciones sociales que van creando históricamente a los sujetos en sus conquistas, también en sus conflictos y problemas que contienen también su final, al decir de Lefebvre (2013).

En realidad, el espacio social "incorpora" los actos sociales, las acciones de los sujetos tanto colectivos como individuales que nacen y mueren, que padecen y actúan. Para ellos su espacio se comporta a la vez vital y mortalmente: se despliegan sobre él las prohibiciones; después mueren, y ese mismo espacio contiene su tumba (p. 93).

De esta forma, consideramos el habitar como una forma de construcción de un espacio social y que posibilita, en el encuentro de una comunidad, un relato histórico que la dota de un proyecto para el futuro. “... el espacio adquiere un papel central en tanto expresión concreta y tangible de lo realizado por una sociedad en un momento histórico dado y que siempre será heredado socialmente a las generaciones por venir" (Lindón, 2012, p. 592). El barrio visto como es espacio social central en la creación de una historia en común no es ni puede ser visto como un elemento de contexto; es, en justicia, el elemento totalizador que reúne y contiene al sujeto histórico.

Para mayor abundamiento, agregamos la memoria de origen obrero como una cuestión central en el análisis que nos proponemos, particularmente centrados en la adquisición de la vivienda, uno de los bienes de tan difícil acceso como, por otra parte, decisivo a la hora de entregar un "lugar" en la ciudad, resultando el medio para adquirir estatus de ciudadano con plenos derechos en una urbe moderna e industrial como la Valdivia de mediados del siglo XX. Esto es evidente en el caso de las industrias estatales, como la siderúrgica Huachipato que “... destacó por promover entre sus trabajadores y familias las facilidades para adquirir una vivienda, educación, estabilidad laboral y, por sobre todo, movilidad social ascendente" (Brito \& Ganter, 2014, p. 35). En nuestro caso serán muchos más los esfuerzos por conseguir este anhelado objetivo: la vivienda en propiedad.

Respecto a la vivienda, el siglo XX tiene a este aspecto como un problema clave a la hora de articular los procesos de modernización. Particularmente y tras la cuestión social, el Estado se hace cargo de manera progresiva del asunto, primero con la Ley de habitaciones obreras, luego con la creación de la Caja de la Habitación Popular, hasta llegar a la Corvi y posteriores políticas públicas que se proyectan hasta las actuales reparticiones (Raposo, 1999; Valencia, 2012). A pesar de los importantes avances en torno a este asunto, queda pendiente ver las formas colaborativas de producción de barrios, como el caso que presentamos, buscando relevar el rol de las comunidades en la producción de barrios modernos. 
En este sentido, los constructores de ciudad, es decir las personas, tienen una manera específica de definir sus relaciones en la situación que les toca vivir, en el caso de la relación trabajador-empresario o ciudadano-Estado ésta se realiza en permanente conflictividad, dada la presión que los sectores populares ejercen por obtener mayores derechos (Romero, 1990), cuestión que no impide la colaboración en algunos momentos y casos, tal como veremos en el barrio Arica ${ }^{2}$, ambas situaciones, conflicto y colaboración se presentan en su etapa fundacional.

En este texto, y enmarcados en el proceso de modernización capitalista de tipo industrialista que hemos referenciado (Touraine, 2012, pp. 135-149), buscamos incorporar la memoria de los obreros y obreras que le dieron vida a un nuevo barrio en la ciudad; desde sus recuerdos y vinculados a la construcción de su habitar y su devenir como ocupantes del territorio. En esa línea, la pregunta que vehiculiza este texto se refiere a cómo se fue constituyendo un medio nuevo, estableciendo formas de vivir ligadas a la cultura obreraindustrial, propia de los habitantes asociados a la modernidad que el Estado buscaba imponer, a través de la implementación del modelo de desarrollo conocido como sustitución de importaciones.

Es así como hemos recurrido a un trabajo de historia oral que incluyó a los habitantes más antiguos del barrio Arica, hombres y mujeres de sobre setenta años, con ellos realizamos entrevistas en profundidad además de talleres con cartografías participativas y de fotografía. Por otra parte, hemos recurrido a archivos de prensa, en particular de El Correo de Valdivia durante el período de estudio y revisión de documentos depositados en el Conservador de Bienes Raíces de Valdivia. De esta forma se configura una metodología con una serie de fuentes de primer orden que nos sustenta para responder a la pregunta que centraliza esta investigación.

Para viabilizar esta propuesta hemos elegido un caso de estudio: el barrio Arica, que nace a fines de la década del cuarenta y -desde ese tiempo- recorre los diferentes momentos e hitos de la historia del territorio, marcada por terremotos, inundaciones, procesos políticos y sociales, configurando formas de organización social y comunitaria que fueron asentando a estos nuevos valdivianos; este barrio tiene como particularidad la autoconstrucción en contexto del trabajo asalariado, cuestión poco vista en otros conjuntos de la ciudad que son construidos por la industria (Brito et al. 2018) o por el Estado (Hidalgo et al. 2007) cuando se trata de trabajadores formales; o de autoconstrucción en casos de tomas de terrenos o vivienda informal por población no contratada o marginalizada (Garcés, 2002).

En particular, tratamos este estudio desde el origen del barrio en 1948 hasta 1960, cuando se trastoca el proceso de organización social y la actividad barrial propias de la vida comunitaria, ello producto de la deflagración causada por el gran terremoto de 1960 (Rojas,

El barrio Arica está ubicado al sur este de la ciudad, conformado por dos vías, la misma calle Arica y Pedro Ruiz Manríquez, regidor de Valdivia en el período 1909-1912, además cuenta con una plazuela sin nombre y una cancha de fútbol al final de la calle Ruiz Manríquez. 
2018) y la inundación del sector producto de ello (Castedo, 1998; Hernández, 2011), es decir, el origen y el desarrollo del barrio en el período fundacional se cierra con una catástrofe natural que, afortunadamente, no logra detener su existencia, pero genera un complejo escenario para la subsistencia de los vecinos y vecinas y define una nueva etapa en la historia de la comunidad.

De esta manera presentaremos los puntos esenciales que han marcado a los habitantes de este sector de la ciudad, el origen industrial que los instaló social y económicamente, la memoria de su habitar en el barrio y, por último, el territorio creado a partir de su trabajo como habitantes-trabajadores. Finalmente referiremos algunas conclusiones para responder a la pregunta inicial planteada en esta introducción.

\section{EL ORIGEN INDUSTRIAL}

La ciudad de Valdivia, hacia mediados del siglo XX, había sorteado un sinnúmero de dificultades para instalarse como un enclave industrial en el sur de Chile, ello fue posible por múltiples motivos, entre ellos la inmigración europea -alemana en su gran mayoríapresente desde mediados del siglo XIX y su fuerte actividad industrial y comercial en la zona (Almonacid, 2013), también por su situación cercana a la costa mediante el puerto de Corral, que la convertía en un punto importante para la entrada y salida de productos en una época marcada por el mercantilismo.

De esta forma, el siglo XX trajo consigo fuertes cambios que configuraron un paisaje moderno y progresista al decir de los cronistas y viajeros. Alfonso (1900) advierte la característica ya evidente de ciudad industrial, en el tono del visitante propio de su época, profundamente admirador del progreso fabril que marcará el siglo que entraba con fuerza en esta ciudad.

Era la esbelta ciudad, reclinada graciosamente a ambas orillas del pintoresco rio, con sus fábricas, sus casas alegres, su movimiento industrial. Corónala, como faro de progreso, visible a la distancia, la blanca, empinada chimenea de la gran fábrica de Anwandter Hermanos. La progresista ciudad produce, desde el primer momento, en el viajero chileno, una impresion original.

Figúrasele estar en otro país: tan distinto es el panorama que ella, presenta, como estilo i como situacion fluvial, de cuantas ciudades pueblan el territorio de la República (p. 16).

Ese proceso de modernización está en el centro del relato que aquí se expone, mayor aun producto de la necesaria reinvención después del gran incendio de 1909, pues tal como señala Pérez (2010) la destrucción del centro cívico de la ciudad fue prácticamente total, considerando que la mayor parte de los edificios e infraestructura urbana contemplaba madera. 
Valdivia quería ser otra ciudad y la forma en que se fueron adecuando los distintos sujetos sociales a ese proyecto modernizador fue, a la vez, complejo y desafiante.

Ese proceso modernizador continuó desarrollándose en Valdivia luego de refrendado el cambio de paradigma, desde el liberalismo clásico imperante en el siglo XIX (Carmagnani, 1998) al proceso que llevó a Chile al industrialismo con creciente participación estatal tras la crisis mundial de 1929 (Salazar, 2003); de esta forma, el país tomó un rumbo que lo instaló en función de nuevos conceptos, ahora se hablaba de desarrollo, industrialización, nacionalización, entre otros, todos ellos marcaban el camino de los nuevos tiempos (Cavarozzi, 2017). Específicamente, la ciudad y su entorno se caracterizaron por acoger industrias ligadas a los rubros alimentación (molinos, cervecerías), con el tiempo se fueron complejizando y acogieron curtiembres, calzado y astilleros, intentando la siderurgia en Corral (Blancpain, 1974).

En particular y para la ciudad de Valdivia, la actividad industrial se constituyó en el borde río, por razones de accesibilidad a las mercancías e insumos en una época en que las obras públicas eran muy menores o inexistentes. Al respecto el ramal ferroviario Valdivia-Antilhue solo estuvo operativo en 1906, bastante tardío si consideramos la pujanza de la industria valdiviana, ya consolidada en esa época ${ }^{3}$; por otra parte, el primer puente que conectó la ruta longitudinal con Valdivia solo estuvo habilitado a partir de 1945, nos referimos al puente sobre el río Calle-Calle.

Centrados en el espacio que nos convoca, el final de la avenida General Lagos, es decir, la calle Arica, siempre en paralelo al río Valdivia, tuvo importantes instalaciones industriales, el hito fundamental lo constituyen, a partir de 1920, las industrias navieras Haverbeck y el astillero Arens, que se instalaron en el borde río del sector; Arens también constituyó un terreno específico para la siembra y crianza de animales y la producción de hortalizas. Años más tarde ese terreno fue comprado por la Municipalidad de Valdivia a la familia Arens, particularmente a Elsa Arens, para vendérselo a un comité de familias que originaron la actual población en la calle Arica.

En términos económicos, la industria más destacada del sector fue el astillero Haverbeck, empresa que hizo importantes innovaciones técnicas, incorporando la soldadura en cascos de fierro y empleando a trabajadores del área circundante. Esta empresa tiene tal despliegue que incluso el islote frente a ella es utilizado para radicar a cuarenta familias, grupo que hubo de emigrar tras el terremoto y tsunami de 1960 (Guarda, 2001).

Por otra parte, desde 1928 se relata la actividad existente en el sector donde se construiría el barrio, destacando fuertemente el rubro maderero, que hasta el día de hoy marca el barrio, aunque en la actualidad a través de la presencia de chipeadoras y acopio de rollizos de madera para la exportación. A través del balseo y desde los bosques precordilleranos, las

Almonacid (2013, p. 50) indica 62 establecimientos industriales en la comuna de Valdivia en 18 rubros diferentes para 1909, año del gran incendio de la ciudad, es decir, Valdivia efectivamente estaba constituida como una urbe industrial en el sur de Chile a inicios del siglo XX. 
instalaciones de la barraca Jünemann fueron las primeras transformaciones del paisaje, al depositar sendos castillos de madera que comenzaron a atraer a los trabajadores valdivianos. Según testimonios de los balseros así lucía el sector:

... y luego se volvían a amarrar para mandar nuevamente por el río hasta Valdivia, más específicamente a calle Arica en el sector Los Canelos, donde Felipe Jünemann poseía una barraca y una cancha de acopio de vastas dimensiones junto al río... En idéntica dirección apuntan las palabras de Juvenal Fuentealba, quien sostiene que "Don Felipe Jünemann compraba y acanchaba en Los Lagos, amarraban la madera que aserraban arribita de la lancha y llevaba por río a Valdivia, amarraba don Pedro Godoy, que era el "mentolatum" [ayudante en múltiples tareas] de Jünemann, él calificaba, encastillaba, cuidaba, amarraba y balseaba (Moya \& Vásquez, 2014, p. 72-73).

El espacio referido fue una de las zonas de desarrollo industrial del siglo XX, territorialmente obedece a una expansión del proyecto modernizador iniciado a fines del siglo XIX, los enclaves originales fueron Collico e Isla Teja, la zona de primeras instalaciones industriales. El sector que referimos es un sector incorporado a la urbe que deviene de la progresiva instalación de industria en el borde río y que promueve -sin buscarlo, pero junto con ello- el poblamiento de áreas que eran parte de la ruralidad, a extramuros de la ciudad.

La calle Miraflores, entonces, es la primera en aparecer en el sector con vivienda obrera autoconstruida muy ligada a la actividad del astillero, la barraca y otras fábricas y talleres. Resulta importante destacar que el sector va generando otros espacios que la ponen en proceso de urbanización, por ejemplo, la apertura de la Escuela Industrial de Valdivia, al final de la calle General Lagos, en 1934 y que posteriormente se integró al proyecto de la Universidad Técnica del Estado, hasta 1980, cuando se anexa a la Universidad Austral de Chile constituyendo el actual campus Miraflores, revitalizando la zona ${ }^{4}$. El establecimiento, en su origen, es parte de la iniciativa pública, si bien orienta sus actividades a los rubros más apreciados por la industria valdiviana privada: la curtiembre y la carpintería, con el tiempo fue ampliando sus especialidades (Muñoz, 1987, pp. 74-75).

Con el paso de los años, pequeños y medianos emprendimientos se instalan en el borde del río a continuación de los primeros y más grandes ya mencionados, talleres y fábricas de manufacturas tuvieron establecimientos en el barrio, uno de los casos destacados es cecinas Schwencke, pues se instala en la calle Arica justo después del terremoto, cuando todas las empresas cierran y se van. Esta fábrica llevaba, para ese entonces, poco más de diez años en Valdivia y significó la continuidad de la actividad laboral en el área.

4 Creada por el Decreto 3.177 del 19 de abril de 1934, inaugurada en octubre del mismo año. 
El barrio Arica, desde su origen, tiene particularidades en relación con la constitución como conjunto de viviendas, el carácter cogestionado entre tres actores fundamentales: los trabajadores devenidos en nuevos propietarios y habitantes, la institución municipal representando al Estado y las empresas e industrias que ocupan el territorio con nuevas formas de relaciones sociales.

En particular, el barrio Arica se constituyó en esa tríada de intereses y esfuerzos, como lo señala el documento citado a continuación, el Municipio es un actor vital en ese proceso y es quien asume la tarea de generar acciones para conseguir el primer elemento fundamental, la propiedad para la creación del barrio.

En Valdivia a veintiocho de mayo de mil novecientos cuarenta y ocho, siendo las once horas en la Sala de la Alcaldía se procedió al remate de la propiedad municipal, ubicada en calle Arica de esta ciudad, que ha de lotearse en cuarenta y cuatro sitios de conformidad al plano elaborado por el Departamento de Obras Municipales, en cumplimiento al acuerdo adoptado por la Ilustre corporación en sesión ordinaria del veinte de noviembre próximo pasado según lo dispuesto en el Decreto número veintiocho del cinco del presente que autoriza la subasta del inmueble (Compraventa Valentín Barrientos Barrientos a Ilustre Municipalidad de Valdivia).

El remate se produjo luego de publicitar el citado decreto en El Correo de Valdivia y se fijaron carteles en el lugar de la actual población. La historia del terreno como propiedad municipal es algo más antigua, esta corporación se hizo del predio el 20 de noviembre de 1942 mediante la permuta de éste con la Caja de la Habitación Popular, trato realizado en la notaría de Luciano Hiriart Corvalán en la ciudad de Santiago 5 .

Es llamativo que en el decreto municipal se imponga la obligación de construir una casa habitación en el sitio rematado, ello en el plazo de dos años una vez suscrito el contrato, sin poder transferir el sitio a un tercero durante diez años y que los nuevos propietarios no tengan bien raíz de ningún tipo. Con ello se intenciona la construcción de viviendas al reconocerse la falta de ellas para la población más pobre de la ciudad.

Es importante consignar que sea la institución municipal quien impulse este tipo de políticas, resguardando una serie de medidas para que accedan a la propiedad las familias obreras que no están en condiciones de costear la compra de un sitio; por otra parte, define como obligación del nuevo dueño la construcción de la vivienda, es aquí como la cogestión se impone como la manera de lograr la ansiada y necesaria casa. Para abundar en esta política, el Decreto 42 del 29 de diciembre de 1947 de la Asamblea Provincial Subrogante,

5 E inscrito a nombre de la Municipalidad de Valdivia fojas 267 número 283 del registro de propiedad del Conservador de Bienes Raíces de Valdivia, con fecha 18 de marzo de 1948. 
Intendencia de Valdivia ratificó el acuerdo municipal mencionado (ratificación solicitada por la Municipalidad), el que votaron a favor tres cuartas partes de los regidores valdivianos; con esta gestión se confirma la anuencia de diversas instituciones para enfrentar el grave problema de vivienda que afecta a la ciudad en aquellos años.

Por último, el que se estipule un registro abierto en la Alcaldía para las personas que cumplen y se comprometen con los requisitos nos habla de la definición expresa de otorgar los sitios a determinadas familias, pues solo los inscritos en ese registro pudieron participar de la subasta, el mecanismo del remate entonces, fue un modo legal de traspasar la propiedad desde el municipio a las familias trabajadoras, lo fundamental fue disminuir la presión por vivienda desde la institución municipal, y lograr el derecho a la vivienda en propiedad por parte de los obreros. Cabe destacar, en algunos relatos de vecinos y vecinas, se señala que desde 1942 había gente pensando en la construcción de casas.

Respecto al estamento que deviene en vecino del nuevo barrio Arica, es un grupo de origen obrero, que no tuvo -de manera significativa entre sus primeros habitantes- un contingente de migrantes campo-ciudad, más bien fue un grupo que formó parte de esa antigua formación de barrios surgidos al calor de la industrialización en la ciudad y a principios del siglo XX. En ese sentido relevamos las señas fundamentales de su instalación, como lo señala la vecina Auda Carabantes: "mi padre hizo esa casa cuando tenía 23 años, sacando la cuenta, recordándome, y mi padre trabajaba en la industria Jüneman y Balanda, era una industria de maderas". Muchos relatos sugieren una relación directa entre el trabajo en las empresas e industrias cercanas y el proyecto de construcción de viviendas en la zona.

Un primer elemento destacado sobre el origen del barrio tiene que ver con la pertenencia a la fábrica de zapatos Weiss y a la barraca Jünemann, establecida la primera en el aledaño sector de Barrios Bajos y en el mismo sector de Arica la segunda. A pesar de ello, la memoria de los primeros habitantes releva el primigenio carácter rural de la zona donde se instalaron las viviendas, definiendo una relación laboral entre la población inmigrante europea y los chilenos campesinos en el momento en que la zona está industrializándose.

... parcelas de gringos, estaban por allá atrás, a la crianza de animales, colindaba casi ahí (Huachocopihue), colindaba con Liewald, de ahí venía Kunz, atrás era una vega, una pampa y ahí criaban. Trabajaba si, (la madre) en unas hortalizas de Liewald también, porque esa parte era como una quinta y acá adelante había un manzanal, la quinta tenía toda esa parte ocupada, trabajaban mi mamá y mi tía, las dos (Juan Adreoli).

En este recuerdo del origen está presente un fuerte rol gestor por parte de los trabajadores para hacerse de terrenos donde edificar. Mediante la auto-organización de un núcleo de trabajadores del calzado se fueron estableciendo lazos informales con los dueños de un predio rural a las afueras de la ciudad, aquí cabe destacar las carencias del Estado para dotar de viviendas a los crecientes grupos de trabajadores urbanos, la falta de institucionalidad 
pública fue siendo suplida por articulaciones propias que tuvieron una proyección hasta la década del setenta, con la ola de "tomas de terreno" que buscó instalar en el país la vivienda autogestionada y, de paso, construyendo un nuevo sujeto social: el poblador (Garcés, 2002).

La instalación del barrio Arica muestra una manera de habitar que refleja la iniciativa y empuje de la clase obrera, dispuesta a autoconstruirse el hábitat, en ello reclama al Estado derechos y presencia, pero lo hace desde la acción, como se evidencia cuando se decide cerrar la plazuela del nuevo barrio: "Para el inmediato cierre de esta plazuela, uno de los vecinos ofreció la madera necesaria gratuitamente” (El Correo de Valdivia, 15-05-1953). Ahora bien, sin mayores organizaciones sindicales o barriales propiamente constituidas, esta acción autogestionada carece de experiencia política, cuestión que refiere los aprendizajes que las clases populares van adquiriendo, pues a los pocos años vemos la instalación en el barrio de agrupaciones que remiten a la necesaria colectivización de los trabajos.

Conversamos con don Gumercindo Monsalve Ojeda, primer presidente del Comité de Adelanto, persona que conoce desde sus raíces las necesidades de la población. En primer lugar, nos dice, deseamos que se pavimente la calle Arica, la que en invierno queda en estado intransitable, pues el subsuelo, que es ripio, se convierte en barrizal. Deseamos que se rellene con ripio la única calle que tiene la población; que se coloquen soleras de madera en las veredas, las que se han arreglado sólo con ayuda vecinal, pues el municipio no ejecuta trabajos desde el año 1952 (El Correo de Valdivia, 2-12-1953, p. 7).

Volviendo al asunto del origen, éste transita entonces entre lo rural y la nueva instalación urbana, las historias de lodazales, falta de servicios públicos como electricidad, agua potable o alcantarillado y el aislamiento respecto del centro cívico de la ciudad se transmiten en la memoria pobladora, trasuntan en temas como caminar varias cuadras para encontrar transporte público, indicando las dificultades que debieron enfrentar para habitar en este antiguo territorio de chacras. El paso a lo urbano, en lo sucesivo, entrega la idea de modernidad, de progreso, de aspiración por incorporarse a la ciudad y, por lo tanto, fue marcando el inmenso trabajo que se debió desarrollar para lograrlo.

Por otra parte, el rol de los industriales del área está recogido en la memoria de los habitantes, primero y principal por la ocupación en las empresas cercanas al área de construcción del barrio. De esta forma asoman tres fábricas que son ampliamente señaladas como las fundamentales en este sentido: la barraca Jünemann y Balanda, el astillero Haverbeck y Skelweit, Sonavela S.A. y Calzados Weiss, cabe destacar que la primera constituyó una sociedad inmobiliaria en 1948 (El Correo de Valdivia, 2-06-1948, p. 5), aunque la barraca no se encuentra asociada directamente a la construcción de las viviendas, algunos vecinos la recuerdan como una empresa colaboradora en la edificación de las casas, aunque los trabajadores vinieran de otra empresa: "mira, la mayoría eran trabajadores de la fábrica Weiss, que antes quedaba acá en Pérez Rosales... después se fue transformando, antes no era poblado" (Gladys Aguilar). 
Por otro lado, el rol de otra de las empresas fue relevante: "son grandes los sitios, muy grandes, él (Felipe Jünemann) les dio todas las facilidades para que saquen madera, mi madre todavía tiene guardadas las boletas donde compró mi papá todas las maderas" (Auda Carabantes). Es así como el origen del barrio se encuentra ligado a diferentes industrias de la zona, otro vecino señala: "había tres caballeros que trabajan donde Jünemann y la misma firma les hizo sus casas a ellos... con el mismo modelo" (Antonio Limunao).

En ese mismo sentido, algunos vecinos relatan su relación con el astillero Haverbeck, pese a que éste tenía viviendas en el islote existente frente a la planta industrial, algunos habitantes de Arica apuntan su relación con esta empresa, como es el caso de la señora Fresia Pérez, quien señala la llegada de su familia al barrio desde aquel islote frente al astillero mencionado: "entonces nosotros vivíamos en el islote, es que mi papá trabajó cuarenta años ahí, toda la vida... era bodeguero en la compañía naviera”.

Si bien escapa a esta investigación, no es menor señalar el vínculo familiar que existía entre las familias alemanas presentes en la zona, tanto la familia Kunz como la familia Liewald tenían propiedades para el cultivo de hortalizas y frutas, producción de cecinas y leche, ambas se encuentran emparentadas en algún punto; del mismo modo hay parentesco entre la familia Kunz y los Weiss, propietarios de la fábrica de zapatos de donde proviene una gran parte de los vecinos fundadores del barrio Arica. Estas relaciones familiares pudieran estar en la explicación de la radicación de los obreros en la zona, aunque se necesita más investigación para afirmarlo ${ }^{6}$.

La instalación de las familias en el barrio obedeció a la pertenencia de los trabajadores a empresas de la zona, ello perduró durante todo el período fundacional de la población, cuestión que contribuyó a consolidar las relaciones entre los vecinos y vecinas.

\section{EL TERRITORIO CREADO Y REINVENTADO}

Como último punto, y tal vez el de mayor significación, nos referiremos a algunos elementos de la historia pobladora que nos dan luces de los procesos que, desde su relevancia social, son señalados por los habitantes y sus ejercicios de memoria; los elementos que relatamos están siempre ligados al territorio, pero en contexto de creación y/o reinvención, cuestión que los contiene como grupo y les otorga una identidad específica como comunidad.

Para ello recurrimos a cartografiar los lugares importantes para la comunidad, tanto los del pasado como los del presente, en función de aquello hemos definido cuatro categorías que apuntan a la resignificación: la memoria trabajadora, el carácter ribereño del barrio, la comunidad organizada y la tragedia del terremoto. La Fig. 1 considera los lugares que sustentan estas categorías.

6 Historia de Valdivia https://historiadevaldivia-chile.blogspot.com/2016/07/familia-liewald.html Recuperado el 16 de julio de 2018 . 


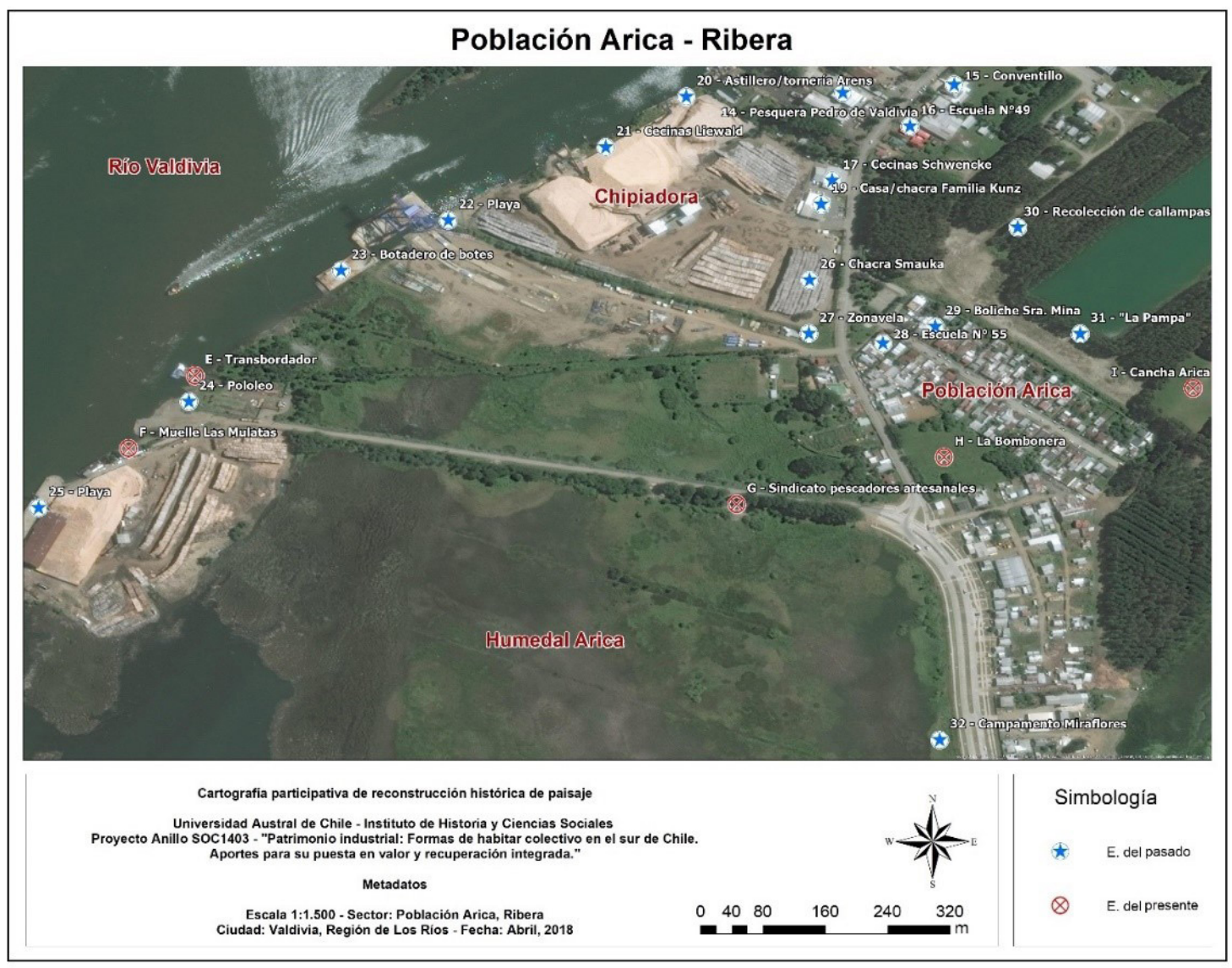

Fig. 1. Cartografía participativa barrio Arica, el autor.

\section{La memoria trabajadora}

En esta memoria pobladora subsiste fuertemente el origen obrero de sus habitantes, mencionando constantemente sus empleos originales, en especial la fábrica de zapatos Weiss, la barraca Jünemann y los diversos talleres del sector, también algunos astilleros como Arens y Haverbeck; pero, por otra parte, subsiste el recuerdo de los primeros vecinos que tuvieron, dedicados a las chacras y lecherías como las de Liewald y Kunz, entre otras y cómo eso repercutió en sus dinámicas de vida, presentes en el carácter semi rural de los primeros años y semi urbano que adquiere producto de la construcción de las viviendas y del barrio.

Este barrio fue un espacio de tránsito entre las chacras y lechería del paisaje inicial, que incluía la producción de hortalizas en los amplios patios de las viviendas, -cuestión que se encuentra fuertemente anclada en su recuerdo-, tanto por el autosustento y el comercio en ferias y espacios públicos que hoy ya no se realizan, como por el trabajo de hombres y mujeres realizado en esas huertas, caracterizando ese andar entre campo y ciudad que identificó al barrio en sus primeras décadas: "eso era todo campo, estaba la lechería ahí" (cartografía participativa). 
Esta primera situación es perfectamente observable en la Fig. 1, si miramos los lugares del pasado que son relevados por los vecinos y vecinas, nos llevan directamente a espacios laborales de tipo industrial y a las chacras; situación especial es la de la fábrica de zapatos Weiss, el origen de la mayor parte de las familias, que se encontraba a unas quince cuadras de distancia en Barrios Bajos y por ello no aparece en la imagen.

Una cuestión de vital importancia para este estudio, y que guarda estrecha relación con el carácter obrero del barrio es la autoconstrucción de las viviendas, porque si bien hemos definido la colaboración entre diversos agentes para la producción de la propiedad y las viviendas, el barrio tuvo un aspecto de suyo relevante: la construcción material de las casas por parte de los vecinos, ya sea en sus horas libres o en los fines de semana y compelidos por las condiciones climatológicas y por el contrato con la Municipalidad, esta fue una obra fundamental en los primeros años.

Julio Acuña, Daniel Pacheco, Eliodoro Aguilar, Enrique Salazar, Antonio Limunao, Ricardo Soto, Alamiro González, la mayoría trabajadores de la fábrica Weiss... este grupito trabajaba en esa fábrica (Weiss), entonces se hicieron amistades, ellos, por lo menos, uno de los que nombré es mi papá, y mi papá era hijo de la señora que estaba a cargo de todo este campo, entonces así fueron haciendo amigos, conversando y fueron a hablar con la Municipalidad, hicieron que esto se los dieran a ellos, se los vendieran a ellos (municipio) y ellos construyeron (trabajadores). Hicieron casas, todas las casas eran iguales, de segundo piso en este lado... de $12 \times 48$ y todos son iguales (Gladys Aguilar).

En ese mismo sentido cabe destacar la ayuda de unos con otros en la construcción de las viviendas, pues si bien fue el cabeza de familia el responsable de la obra muchas veces fue la concurrencia de los vecinos y amigos lo que posibilitó sacar adelante la tarea. Importa señalar que los saberes en términos constructivos de los propios habitantes son elogiables, pues décadas después y terremotos de por medio, muchas de estas viviendas siguen estando en pie: "no, si ellos construyeron solos, como te dijera, hicieron un formato, ya, hicieron una casa y ahí se fueron acompañando ellos mismos" (Gladys Aguilar).

Pese a las condiciones del trabajo en esos años, es decir, los bajos salarios y pocas regalías y beneficios para los trabajadores, tal vez este mismo hecho de la autoconstrucción colaborativa ayudó a una valoración importante de los vecinos y vecinas respecto a su identidad de familias trabajadoras, cuestión que se mantiene y relata en los testimonios recabados y que se conserva incólume en el relato de la memoria fundacional del barrio, tal como lo vimos antes.

La cultura obrera aparece progresivamente en el barrio, incluyendo los problemas que se asumen producto de la vida en un barrio, desde muy temprano estas situaciones se comentan incluso en la prensa, haciendo alusión al alcoholismo y la indefensión, pero al mismo tiempo reclamando la presencia de las autoridades, a quienes reconocen como los primeros responsables de la solución de los problemas del vecindario. 
Desde hace mucho tiempo que se nos ha prometido dejar completamente condicionada la plazuela de la población y hasta el momento no se ha hecho ningún arreglo...Hasta no hace mucho tiempo este barrio se caracterizaba por su permanente tranquilidad, pero no podemos decir lo mismo ahora, existiendo mucho clandestinaje alcohólico. Son varias las casas particulares donde se arman frecuentes remoliendas (El Correo de Valdivia, 22-01-1950, p. 24).

En efecto, el ocio propio de las comunidades de trabajadores se produce en torno a estas fiestas, más si es en verano, esto genera transgresiones y molestias que se aprecian en notas periodísticas como éstas. Sin duda, dos años después del inicio del barrio, esta comunidad ha entrado fuertemente en la dinámica de una población obrera de una ciudad chilena de mediados del siglo; ello no significa vivir de mejor forma, solo que ha pasado a constituir el paisaje urbano de una ciudad en proceso de modernización.

\section{El carácter ribereño del barrio}

El barrio, desde su inicio, tuvo una estrecha relación con los cuerpos de agua existentes en el lugar. Tanto el río Valdivia y el canal Haverbeck como el humedal Angachilla definieron el carácter de la comunidad, otorgando una parte de las actividades que los y las vecinas fueron desarrollando, tanto en los aspectos funcionales de la vida en el sector, como en cuestiones relativas al ocio y el esparcimiento.

Desde el principio, en este sector de Valdivia, al embarcadero llegaban los botes de la costa a surtirse de las mercancías en los almacenes del barrio Miraflores y, al mismo tiempo, entregaban leña y carbón; no era necesario llegar a Valdivia, creando un tráfico fluvial que potenciaba el carácter periférico de este sector. Esto que persiste en la memoria del barrio fue perdiendo entidad una vez creado el mismo, tal vez sea parte de las tareas futuras del rescate patrimonial valdiviano, recuperar las rutas de embarcaciones por las que obreros y campesinos del siglo XX hacían su vida y construían la economía, el tipo de sociedad y la cultura del territorio.

Entonces había un emporio, emporio se llamaba antes a los almacenes grandes y ahí llegaba toda la gente, venían de alrededor, llegaban en bote a comprar, toda esa gente venía de Futa, de Corral, Niebla, Naguilan, todos esos venían a comprar aquí a Saralegui, toda gente de campo, en puro bote no más venían aquí (al vecino barrio de Miraflores), porque les salía más cerca y corrían vapores chicos y ellos traían su leña (Américo Limunao).

Esta es una primera funcionalidad que el río permite, con ella se constituyó parte importante de los espacios significados por los pobladores, estos lugares dotaron de sentido 
al habitar. Además de ello, los relatos nos hablan de vacaciones, baños y juegos en la playa, donde también se tomaba once, todo ello perdido por el cierre de los accesos hoy puerto Las Mulatas. Recuperar el borde río y su rico potencial de ocio y diversión para las personas es otro elemento de los relatos de los pobladores del sector, que es fuertemente indicado en los testimonios y en la cartografía presentada, y considerado como una deuda para con ellos mismos.

En relación al punto anterior, la prensa nos regala una prueba respecto a una cuestión que puede parecer anecdótica, pero que representó una conquista para la nueva comunidad arraigada en el sector; los y las vecinas accedieron a la ribera del río para celebrar las tardes de verano por encima de las prohibiciones de las empresas propietarias de ese borde, pese a los intentos de impedir los accesos para llegar a la playa, los relatos anteriores nos señalan que esos paseos no se detuvieron (Fig. 2).

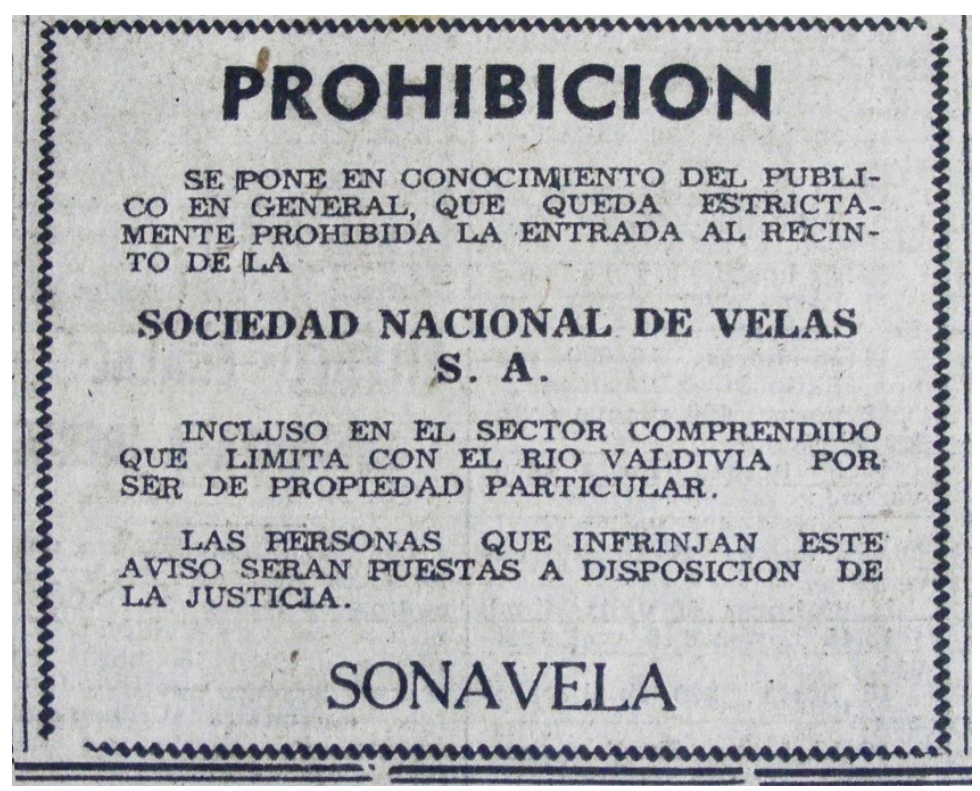

Fig. 2. Aviso publicado en prensa local.

Fuente: El Correo de Valdivia, 10 de enero de 1954, p. 10.

Por otra parte, los humedales representaron otro elemento de la vida en la nueva población, ligados a viejas prácticas de economía local propias del sur de Chile, estas zonas pantanosas fueron utilizadas para complementar los beneficios que el salario de los trabajadores no lograba completar, de esta forma los humedales -así como los bosques en otros sectores- fueron espacios para la recolección, la caza y la pesca, cuestión que, con el paso del tiempo, fue desapareciendo para dar lugar a la economía formal que impuso el Estado y el mercado, otro elemento de la modernización social vivida en el siglo XX.

Esas formas de subsistencia en los humedales consistían en el uso del espacio, por ejemplo, en la crianza de aves y animales de corral, las denominadas pampas fueron 
utilizadas como espacios para la cría de estas especies que contribuían a la dieta de las familias y también como una entrada adicional al salario: "los gansos eran muy delicados, el vecino Ramos tenía gansos, una bandada en la pampa, al aire libre... y después los empezaba a vender" (Fresia Pérez).

Las formas de subsistencia en tiempos difíciles, ya sea por desastres naturales como el terremoto de 1960 o por la pobreza vivida en dictadura, han quedado en el imaginario de los pobladores, ahora resignificado por la restitución como espacio de ocio, aunque conflictuado por la existencia de obras viales que no han complicado su uso en ese sentido. La historia original del barrio y cómo se puede comprender desde el presente pudieran entregar más y mejores ideas para conectar ese pasado con las necesidades sociales culturales de un barrio consolidado en la ciudad.

\section{La comunidad organizada}

Los habitantes del barrio Arica fueron constituyendo, desde su inicio, una comunidad que organizó la vida en consonancia con los tiempos modernos; a través de diferentes experiencias organizativas cuestiones como la educación, el transporte, los servicios básicos o el deporte pusieron a este grupo de pobladores como una comunidad en permanente diálogo con las autoridades municipales. Las escuelas tuvieron una breve existencia, pero funcionaron al inicio en casas de vecinos: “... dueños de casa prestaban dos o tres piezas como para que hagan algo, aquí existió la escuela 72, aquí en la población y la escuela 49 y esas siguen existiendo, la escuela 72 yo sé que está en la Corvi” (Gladys Aguilar).

Es así como las escuelas públicas de mayor complejidad no están presentes en el programa del barrio, por lo tanto, se debió recurrir a otros establecimientos cercanos para ello: "antes del terremoto mis hermanas iban al colegio María Auxiliadora que era exclusivamente para gente pobre que estaba donde está el Domus Mater (calle Bueras, Barrios Bajos) y mi hermano iba a la escuela 4 que era donde está el Insat" (Auda Carabantes). Es así como los niños y jóvenes debieron salir del barrio para lograr mayor escolarización.

Es importante rescatar la vida social de este barrio y sus acontecimientos, que han quedado grabados en el recuerdo, con ellos se ha elaborado una memoria colectiva que remata en su presente. Al respecto podemos destacar el adoquinamiento de las calles hacia 1970, el club deportivo y su labor de unión del barrio celebrando fiestas patrias y navidades además de los partidos habituales, desde los noventa se levanta el agua potable y electricidad domiciliaria, terminando con los pozos negros, además del asfalto de las calles, dotando al barrio de un perfil actualizado y acorde al estándar de las poblaciones chilenas de hoy.

En especial el club de fútbol Deportivo Arica significó un importante logro para la organización comunitaria del nuevo barrio, éste surgió al poco tiempo de iniciarse la construcción de las viviendas que le dieron vida a la población: "la celebración del aniversario del Deportivo Arica, el 9 de octubre del año 1949... hubo tiempos buenos en que se celebraba, 
un campeonato, un partido y todos esperando el baile allá en la sede de La Esperanza" (Ernesto Barriga). Es importante señalar lo inicial de la existencia del deportivo, prácticamente nacido con el barrio y su fundación, marcando el fuerte lazo entre barrio, ocio e identidad local.

Cabe destacar que el fútbol, en cuanto organización deportiva de tipo popular, es otra muestra de integración social en el marco de la cultura obrera, y que define propiamente un proceso de modernización, pues se conecta a un relato general de los trabajadores que se reconocen en la práctica deportiva o en su seguimiento como aficionados, dejando atrás las costumbres y diversiones propiamente campesinas (Elias \& Dunning, 1992).

Como ya señalamos respecto al aniversario del Deportivo y su rol en las formas de socialización barrial; ahora se aprecia en la Fig. 3 cómo los vecinos del barrio Arica fueron encontrándose con comunidades cercanas, el barrio Miraflores en particular -aún más antiguo-, en uno de sus espacios más característicos: la sociedad mutualista La Esperanza, se les puede ver reunidos en distintas celebraciones y en reuniones de fin de semana.

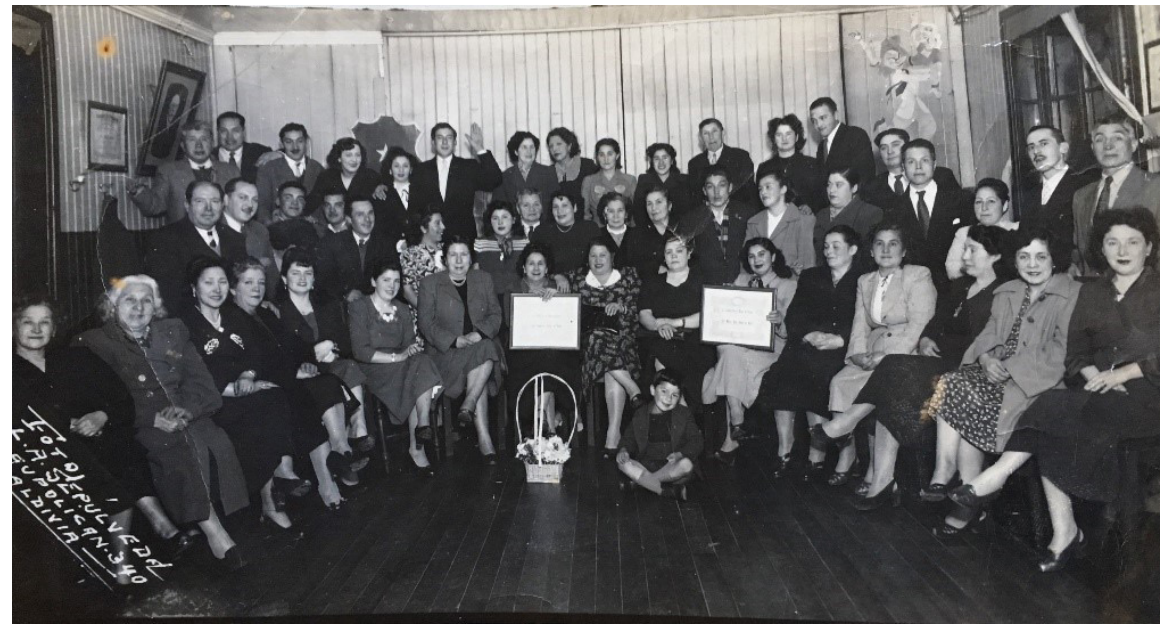

Fig. 3. Sociedad Mutual La Esperanza.

Fuente: Archivo Sra. Fresia Pérez.

De esta forma, el barrio se aprendió a conocer en el entramado de posibilidades dadas por el ocio y la oportunidad de realizar actividades juntos, éstas no solo pasaron por el ocio, el deporte, la lucha por el bienestar, un punto importante fue la escolarización de los niños, otro signo relevante de modernización, muy conectado con el discurso educacionista de la época representado en el lema del Presidente Aguirre Cerda "gobernar es educar”.

De esta manera, sin lugar a duda el barrio Arica manifestó su interés por incorporarse a la ciudad, por sumarse al proyecto de modernización que imponía lo urbano como condición para integrar esa modernidad, lo hicieron asumiendo los tipos y formas que ello indicaba, resignificando sus prácticas y maneras de vivir; por otra parte, también hicieron uso de su reclamo en cuanto sujetos de derechos en ese proyecto, cuestión que se acrecentó y complejizó con el tiempo. 


\section{La tragedia del terremoto}

El terremoto de 1960 significó un duro golpe para la persistencia del barrio, pero ese cambio drástico en las formas de vida no hizo desistir a los pobladores en su intención de permanecer en la comunidad, de esta forma solo dos familias abandonaron el sector, según recuerdan los vecinos entrevistados, ello en circunstancias del completo anegamiento de las viviendas, aislándolos todavía más del centro que, por cierto, quedó completamente inhabilitado.

En ese contexto, cobró aún más valor el entorno, revalorizando el territorio y haciendo uso de antiguas formas de subsistencia, todavía presentes en la memoria de los campesinos sureños que fueron los antepasados de esta comunidad trabajadora.

Había harta ave, bueno ahora como ya se pudrió la caza también por acá y la caza de coipos, colocaban trampas no más y tan rico que es el coipo, y de patos, si se llenaba de agua acá atrás, el cazador todo lo que pilla mata po', si antes no había desagües, no como ahora, si hasta los cisnes de repente, aunque no son muy buenos, camarones sacaban también, antes del terremoto daba gusto y después, hasta no hace na' tantos años atrás (Américo Limunao).

La gran catástrofe de 1960 fue una prueba para el barrio, tanto el terremoto en sí como el denominado "Riñihuazo", es decir, el desagüe del lago Riñihue por el río San Pedro, que afectó crudamente las zonas bajas de la ciudad de Valdivia, entre ellas el área del barrio Arica (Castedo, 1998). Esta inundación, anunciada con tiempo debido a su preparación para evitar la violencia del torrente, obligó a los vecinos a trasladarse a zonas más altas (Hernández, 2011). La prensa relata detalladamente el traslado desde Arica, Miraflores y Barrios Bajos hacia Huachocopihue y Pampa Kramer: "vehículos de Ejército y Carabineros, camiones, camionetas y vehículos particulares, carretones y cuanto objeto con ruedas se pudo utilizar estuvieron prestos a trasladar a los moradores de dichos lugares y a sus modestos enseres a lugares más seguros" (El Correo de Valdivia, 7 de junio de 1960, p. 1).

Aquí se quedó mi padre, mi cuñado, la finada de mi madre y una sobrina... ellos quedaban aquí, así es que mi padre tenía que arreglar su casa, enderezarla, pero nosotros en septiembre estuvimos como dos o tres meses en Santiago, en ese tiempo nosotros estábamos viviendo en la escuela 3, ahí estaba albergado mi viejo... pero no empezó na' la gente arreglar sus casas, pasaron sus buenos años, a acomodarlas a cómo estaban, todas quedaron chuecas (Américo Limunao).

Una cuestión significativa es constatar que la reconstrucción vino por parte de los mismos vecinos y vecinas, esta vez sin el apoyo de las industrias, completamente destruidas 
por la gran catástrofe, el Estado tampoco se hizo parte y, nuevamente, el esfuerzo de las y los trabajadores del barrio fue vital para restituir el mismo; tal como indica la cita, mucho tiempo pasó para lograr habilitar las viviendas, dadas las dificultades por falta de apoyo.

Como se puede entender, el terremoto de 1960 y sus consecuencias no solo redundaron en la compleja situación de restituir las viviendas y los accesos viales del barrio, el cataclismo produjo un punto de inflexión importante en la vida social, afianzando los lazos construidos en doce años de vida; por otra parte, introdujo un nuevo período en la comunidad, constituyendo su integración a la historia de la ciudad, a través de la valoración de la organización comunitaria ya comenzada. Luego de este momento vendrían cambios económicos, sociales y culturales que se expresarían con fuerza en nuevas organizaciones sociales y culturales, como la junta de vecinos y el club deportivo.

\section{CONCLUSIONES}

Para concluir diremos que los procesos de modernización hicieron posible la configuración de este barrio tal como lo conocemos hoy, pero ello incluye al trabajo comunitario de los pobladores, quienes transformaron sus formas de habitar en relación con los cambios económicos, sociales e incluso físicos que vivió este territorio. Podemos decir que el territorio cambió junto con ellos, desde su origen obrero hasta su incorporación a la ciudadanía valdiviana.

Un hito fundamental de todo el sur de Chile fue el terremoto de 1960, cambiando de golpe el paisaje y las formas de habitar, las empresas cerraron y los capitales se fueron, Weiss se redujo y cambió su planta a Las Ánimas, desapareció Arens y también la fábrica de productos de madera Jünemann, la recordada fábrica Sonavela, además de los almacenes de Saralegui y García en Miraflores, entre muchos otros establecimientos del sector. Ese punto de inflexión marcó decisivamente el persistir, quedarse y afrontar una nueva y dura realidad.

Se debe entender la extensión del espacio habitado más allá de las viviendas e infraestructura urbana; comprender los ríos, humedales y bosques como parte de la historia y espacio de esta comunidad, con ello se puede considerar una nueva etapa en la construcción de una comunidad barrial con identidad histórica, cuestión que la dota de una profundización en su ciudadanización, profundizando el camino de modernizaciones que este grupo de trabajadores y sus descendientes han vivido por siete décadas.

Por último, y en respuesta a nuestra pregunta de investigación, tanto la gestión como la construcción de la vivienda en propiedad son un signo particular del proceso modernizador vivido por esta comunidad, pues mientras se integran como ciudadanos en plenitud de derechos al proyecto que se les presenta, es ese mismo Estado quien los obliga a crear formas de cogestión para incluirse como vecinos de la ciudad, no sin la ambigüedad propia de una estructura estatal insuficiente para atender los derechos sociales, aun así el barrio logra valorizarse en la concreción de sus objetivos desde su condición de trabajadores y trabajadoras. 


\section{REFERENCIAS}

Alfonso, J. (1900). Un viaje a Valdivia. La civilización alemana en Chile. Santiago de Chile: Imprenta Moderna.

Almonacid, F. (2013). La industria valdiviana en su apogeo (1870-1914). Valdivia: Ediciones UACh.

Blancpain, J. P. (1974). Los alemanes en el sur de Chile: 1816-1945. Tesis doctoral inédita, traducida por Yves Jovet, Universidad Austral de Chile: Valdivia. 4 vols. 1162 p.

Brito, A., \& Ganter, R. (2014). Ciudad obrera: persistencias y variaciones en las significaciones del espacio. El caso de la siderúrgica Huachipato y su influencia en el desarrollo urbano del Gran Concepción. EURE, vol. 40, N 121: 29-53. doi: http://dx.doi.org/10.4067/ S0250-71612014000300002.

Brito, A., Cerda, G., Fuente, P., \& Pérez, L. (2018). Industria y habitar colectivo. Conjuntos habitacionales en el sur de Chile. Concepción: Stoq.

Carmagnani, M. (1998). Desarrollo industrial y subdesarrollo económico: El caso chileno (1860-1920). Santiago de Chile: DIBAM.

Castedo, L. (1998). Hazaña del Riñihue. El terremoto de 1960 y la resurrección de Valdivia. Santiago de Chile: Sudamericana.

Cavarozzi, M. (2017). Los sótanos de la democracia chilena, 1938-1964. Las esferas de "protección” de los empresarios industriales: la CORFO, represión a los obreros y la inflación. Santiago de Chile: LOM.

Elias, N. y Dunning, E. (1992). Deporte y ocio en el proceso de la civilización. Madrid: FCE.

Garcés, M. (2002). Tomando su sitio. El movimiento de pobladores de Santiago, 19571970. Santiago de Chile: LOM.

Guarda, G. (2001). Nueva historia de Valdivia. Santiago de Chile: PUC.

Hernández, J. (2011). 1960 memorias de un desastre. Valdivia: Arte sonoro Austral ediciones.

Hidalgo, R. (2007). Cien años de política de vivienda social, cien años de expulsión de los pobres a la periferia de Santiago. En R. Hidalgo y M. J. Castillo (Eds.), 1906/2006 Cien años de política de vivienda en Chile. Santiago de Chile: Ediciones UNAB.

Illanes, M. A. (2006). Cuerpo y sangre de la política. La construcción histórica de las visitadoras sociales (1897-1940). Santiago de Chile: LOM.

Lefebvre, H. (2013). La producción del espacio. Madrid: Capitán Swing.

Lindón, A. (2012). La concurrencia de lo espacial y lo social. En G. Leyva \& E. De la Garza (Eds.), Tratado de metodología de las ciencias sociales: perspectivas actuales (pp. 585-622). México: FCE,

Moya, L. y Vásquez, N. (2014). Relatos de balseros de los ríos San Pedro y Calle-Calle (1930-1960). Valdivia: Serifa-Gobierno regional de Los Ríos.

Muñoz, J., Norambuena, C., Ortea, L., Pérez, R. (1987). La Universidad de Santiago 
de Chile. Sobre sus orígenes y su desarrollo histórico. Santiago: Universidad de Santiago de Chile.

Pérez, J. (2010). La noche triste 13 de diciembre de 1909. Valdivia: Libros El Canelo.

Raposo, A. (1999). La vivienda social de la CORVI. Otro patrimonio. INVI, 14(37), 41-73.

Rojas, C. (2018). Valdivia 1960 entre aguas y escombros. Valdivia: Ediciones UACh.

Romero, L. A. (1990). Los sectores populares urbanos como sujetos históricos. Proposiciones, (19), 268-278.

Salazar, G. (2003). Historia de la acumulación capitalista en Chile: Apuntes de clase. Santiago de Chile: LOM.

Thompson, E. P. (2012). La formación de la clase obrera en Inglaterra. Madrid: Capitán Swing.

Touraine, A. (2012). Crítica de la modernidad. Ciudad de México: FCE.

Valencia, M. (2012). La vivienda popular en Santiago. Cuatro momentos en el siglo XX. Una aproximación desde la biopolítica. Diseño urbano y paisaje, 9(24), 1-16. Recuperado 4 de noviembre de 2019. http://dup.ucentral.cl/pdf/24_valencia.pdf

Williams, R. (2017). El campo y la ciudad. Buenos Aires: Prometeo.

\section{Fuentes primarias}

El Correo de Valdivia. Archivo Ilustre Municipalidad de Valdivia, 1948-1960.

Conservador de Bienes Raíces de Valdivia.

\section{Testimonios}

Auda Carabantes, 63 años, 17 de julio de 2018.

Ernesto Barriga, 73 años, 11 de abril de 2018.

Juan Adreoli, 75 años, 20 de diciembre de 2018.

Fresia Pérez, 70 años, 30 de noviembre de 2018.

Gladys Aguilar, 67 años, 17 de agosto de 2018.

Antonio Limunao, 84 años, 16 de junio de 2018.

Américo Limunao, 70 años, 17 de junio de 2018.

Taller de cartografía participativa barrio Arica, 1 de diciembre de 2017. 